\title{
BMJ Open Electronic nicotine delivery devices, and their impact on health and patterns of tobacco use: a systematic review protocol
}

\author{
Allison M Glasser, ${ }^{1}$ Caroline O Cobb, ${ }^{1,2}$ Lyubov Teplitskaya, ${ }^{3}$ Ollie Ganz, ${ }^{3}$ \\ Lauren Katz, ${ }^{1}$ Shyanika W Rose, ${ }^{1}$ Shari Feirman, ${ }^{1}$ Andrea C Villanti ${ }^{1,4}$
}

To cite: Glasser AM, Cobb CO, Teplitskaya L, et al. Electronic nicotine delivery devices, and their impact on health and patterns of tobacco use: a systematic review protocol. BMJ Open 2015:5:e007688.

doi:10.1136/bmjopen-2015007688

- Prepublication history for this paper is available online. To view these files please visit the journal online (http://dx.doi.org/10.1136/ bmjopen-2015-007688)

Received 15 January 2015 Revised 31 March 2015 Accepted 9 April 2015
CrossMark

For numbered affiliations see end of article.

Correspondence to

Allison M Glasser;

aglasser@legacyforhealth.org

\section{ABSTRACT}

Introduction: E-cigarettes or electronic nicotine delivery systems (ENDS) have recently attracted considerable attention. Among some individuals there is strong debate and a polarisation of views about the public health benefits versus harms of ENDS. With little regulation, the ENDS market is evolving, and new products are introduced and marketed constantly. Rapid developments in manufacturing, marketing and consumer domains related to ENDS will warrant frequent re-evaluation, based on the state of the evolving science. The purpose of this article is to describe a protocol for an ongoing comprehensive review of the published scientific literature on ENDS.

Methods and analysis: We will undertake a systematic review of published empirical research literature on ENDS using the National Library of Medicine's PubMed electronic database to search for relevant articles. Data from included studies will be extracted into a standardised form, tables with study details and key outcomes for each article will be created, and studies will be synthesised qualitatively.

Ethics and dissemination: This review synthesises published literature and presents no primary data. Therefore, no ethical approval is required for this study. Subsequent papers will provide greater detail on results, within select categories, that represent gaps in the literature base.

\section{INTRODUCTION}

E-cigarettes or electronic nicotine delivery systems (ENDS) have recently attracted considerable attention for several reasons. Compared with combustible cigarettes, these (1) deliver nicotine without combustion, (2) are thought to be less toxic, ${ }^{1-8}$ (3) can be used to reduce nicotine craving/ withdrawal, ${ }^{3}{ }^{9-13}$ (4) tend to be less expensive $^{2} 381^{14} 15$ and (5) can potentially help one quit combustible cigarette smoking/ prevent relapse. ${ }^{1-4} 6-815-21$

\section{Strengths and limitations of this study}

- This review systematically synthesises studies related to electronic nicotine delivery systems use across a broad range of study designs and outcomes.

- The results of this study may inform future regulatory action and future research studies.

- This review will be limited to English language and peer-reviewed articles.

- Owing to the volume of studies in the literature base, the literature search was limited to one database.

While there is great variability in the design and performance of ENDS within and across brands, characterising features include the use of a battery or other power source, and a heating element that when activated delivers an aerosol mist from a solution most often containing tobacco-derived nicotine, flavourings and other ingredients. $^{22} 23$ ENDS typically fall into three categories: disposable 'ciga-like' products, rechargeable 'ciga-like' products and larger rechargeable products (ie, personal vapourisers, tank systems). In addition to physical and performance-related differences, these categories of products differ in price, where they are typically sold, and the type of ENDS users that purchase them. ${ }^{14} 24$

Among some individuals, there is strong debate and a polarisation of views about the public health benefits versus harms from use of ENDS. ${ }^{25-27}$ Proponents argue this is a disruptive technology that has potential to speed the demise of the combusted cigarette. From this perspective, ENDS could present an unprecedented opportunity to alleviate the burden of tobacco-related death and disease on a massive scale. Opponents are concerned about minimising unintended 
Table 1 Electronic nicotine delivery systems systematic review study categories and outcomes

\begin{tabular}{|c|c|}
\hline Study category & Outcomes \\
\hline Product features & $\begin{array}{l}\text { Product design } \\
\text { Nicotine, propylene glycol, } \\
\text { flavouring, particulate matter and } \\
\text { other toxicant content }\end{array}$ \\
\hline Health effects & $\begin{array}{l}\text { Effects of: } \\
\text { - Nicotine } \\
\text { - Tobacco-related toxicants } \\
\text { - Non-tobacco-specific toxicants } \\
\text { Impact on: } \\
\text { - Cardiovascular system } \\
\text { - Lung function } \\
\text { - Blood count } \\
\text { - Other physiology } \\
\text { - Cognition } \\
\text { - Abuse liability/addictiveness } \\
\text { - Adverse events } \\
\text { - Cytotoxicity }\end{array}$ \\
\hline $\begin{array}{l}\text { Consumer } \\
\text { perceptions }\end{array}$ & $\begin{array}{l}\text { Awareness } \\
\text { Product perceptions } \\
\text { - Interest } \\
\text { Reasons for use }\end{array}$ \\
\hline Patterns of use & $\begin{array}{l}\text { Ever, current and dual use with other } \\
\text { tobacco products } \\
\text { Initiation/progression } \\
\text { Smoking cessation/reduction } \\
\text { Use among various groups: general } \\
\text { population, youth, young adults, } \\
\text { adults, current smokers, former } \\
\text { smokers, never-smokers, etc }\end{array}$ \\
\hline Marketing & $\begin{array}{l}\text { Advertisement/promotion prevalence } \\
\text { and expenditure } \\
\text { Claims and depictions } \\
\text { Receptivity to advertising/promotion } \\
\text { Marketing channels }\end{array}$ \\
\hline Sales & $\begin{array}{l}\text { Market share/sales volume } \\
\text { - Retail and online availability } \\
\text { - Pricing }\end{array}$ \\
\hline Policies & $\begin{array}{l}\text { Federal, state, local and } \\
\text { organisational } \\
\text { Existing and proposed } \\
\text { - Public support for policy }\end{array}$ \\
\hline
\end{tabular}

consequences such as unforeseen health hazards related to ENDS, dual use that might undermine cigarette smoking cessation and the possibility that ENDS will attract non-users, including youth and former cigarette smokers.

The ENDS market is evolving, with new products being rapidly introduced and marketed. Currently, there is no independent entity charged with monitoring and regulating ENDS products, but the US Food and Drug Administration (FDA) Center for Tobacco Products (CTP) has proposed a rule to deem ENDS as subject to the Family Smoking Prevention and Tobacco Control Act (Tobacco Control Act). ${ }^{28}$ Previous reviews have addressed specific topics, including the health effects of ENDS ${ }^{29-48}$ the impact of ENDS on smoking cessation, ${ }^{38} 49-53$ product features, ${ }^{29} 485455$ consumer perceptions, ${ }^{3456}$ patterns of use ${ }^{34} 57$ and policies. ${ }^{58}$ There are also several published comprehensive reviews about the ENDS literature. ${ }^{59-63}$ However, rapid development in manufacturing, marketing and consumer domains related to ENDS will warrant frequent re-evaluation, based on the state of the evolving science. The purpose of this article is to describe a protocol for an ongoing comprehensive review of the published scientific literature on ENDS.

\section{METHODS AND ANALYSIS \\ Design}

We will undertake a systematic review of empirical research literature published in peer-reviewed journals on ENDS to be updated at regular intervals and on an as-needed basis to inform FDA public comment periods and other policyrelevant information gathering sessions.

\section{Eligibility criteria}

Study design

Eligible studies are experimental studies, quasiexperimental studies, observational studies (including case-control, cohort and cross-sectional studies), case reports, case series, qualitative studies and mixed methods studies providing empirical data on ENDS. Potential other sources will be obtained by emailing experts and reviewing reference lists of included articles.

\section{Outcome measures}

We will accept a broad range of outcomes that will demonstrate the impact of ENDS on individual-level and population-level health. These are listed in table 1.

Published reviews, commentaries, letters to the editor, editorials, practice guidelines, position statements and study protocols will be excluded unless they present original data from the authors. This review will be limited to English language studies published in peer-reviewed journals (not limited to the USA). Preclinical/animal studies will be excluded.

\section{Search methods}

We conducted an initial search in August 2013 using the National Library of Medicine's PubMed electronic database and the following keywords: "e-cigarette*" OR "electronic cigarette" OR "electronic cigarettes" OR "electronic nicotine delivery". We did not specify a starting publication date because ENDS are a relatively new class of tobacco products. Since the initial search, we have conducted regular searches to identify new studies on ENDS and added the medical subject heading $(\mathrm{MeSH})$ term "Electronic Cigarettes" that was introduced in 2015 as well as "vape" OR "vaping" to our list of search terms. Searches will be conducted at regular intervals and on an as-needed basis to inform FDA 
public comment periods and other policy-relevant information gathering sessions. Reference lists of published literature reviews on ENDS will be screened for additional eligible studies.

\section{Study selection}

For the first round of review to determine eligibility, one reviewer will screen the article title and abstract for reference to ENDS. Articles that make it through this round will then be reviewed in full text to determine inclusion into one or more of the following categories: (1) product features, (2) health effects, (3) consumer perceptions, (4) patterns of use, (5) marketing, (6) sales and (7) policies. At the point of data extraction, reviewers will confirm eligibility before entering the study's data in the review. If an article is excluded for multiple reasons, only the primary reason for exclusion will be noted. The hierarchy for identifying the reason for exclusion when multiple reasons exist will be as follows: (1) the article was not available in English, (2) the article was not relevant to ENDS, (3) the study included non-human participants or (4) the study did not include original data. The remaining studies will be retained for inclusion in the systematic review. If a study meets the criteria for eligibility in the first round, but does not fit into one of the seven categories listed above, the team of reviewers will meet to discuss whether additional categories should be added to capture emerging themes in the scientific literature.

\section{Quality assessment}

Randomised studies assessing the impact of ENDS on health effects, consumer perceptions or patterns of use will be evaluated using the Cochrane Collaboration tool for assessing risk of bias. ${ }^{64}$ For other study designs, we will consider the study's applicability or relevance to the literature and note its limitations.

\section{Data extraction}

Data from included studies will be extracted into a standardised form developed in Microsoft Excel by a number of reviewers (AMG, COC, OG, LT, LK, SWR, SF and ACV), with each reviewer completing data extraction for a given category of studies. The form will contain the following fields: (1) study objective(s); (2) study details/methods (including study design, intervention groups, number of experiments, equipment used, setting, puff conditions and measurement conditions); (3) target population; (4) sample size; (5) products tested, if applicable (including number, type, brand name/model, nicotine content and flavour of products); (6) measures; (7) outcomes; (8) limitations; (9) major conclusions and (10) funding source/author disclosures. During this process, the form will be revised if other relevant information is not captured in these fields. In addition, individual reviewers will identify other categories of the review (eg, product features and health effects) in which the study should be included based on the outcomes measured in that study. All communications regarding the addition of studies to other categories will be documented on a web-based project management system available to all authors. This will ensure that studies addressing multiple outcomes are captured in all of the relevant sections of the review.

\section{Data analysis}

Following data extraction, we will create tables with details and key outcomes for each study within each category (ie, product features and health effects). In addition, we will qualitatively synthesise studies by outcomes measured and the main results. We intend to publish subsequent papers on select outcomes to address gaps in the literature base. Given the heterogeneity of the included study designs and outcomes, we do not expect to conduct meta-analyses of study results, assess metabiases or evaluate the body of evidence systematically using a central framework (eg, GRADE). As the evidence base grows, we will re-examine whether there are a sufficient number of similar studies on a single topic to warrant conducting these evaluations.

\section{ETHICS AND DISSEMINATION}

This review synthesises published literature and presents no primary data. Therefore, no ethical approval is required for this study.

\section{Publication plan}

Findings from this systematic evidence review will be disseminated in white papers, policy documents (eg, federal docket submissions), fact sheets and peerreviewed journal articles.

\section{STRENGTHS AND LIMITATIONS}

This review is unique in three ways. First, whereas most other reviews on ENDS have focused on a particular outcome of interest, ${ }^{31} 35364350525356$ this review will systematically synthesise studies related across a broad range of study designs and outcomes on an ongoing basis. Second, the review will be updated regularly and in response to opportunities to inform policy and programme decision-making. Third, the review will highlight gaps in the literature to recommend areas for future research in pace with the rapidly evolving tobacco landscape and evidence base.

Limitations of the review include the restriction of eligible studies to those that are peer-reviewed, indexed in PubMed and available in English language. Owing to the volume of studies in the literature base, the search is limited to one database, and a single author conducts the title and abstract review for a given search. While an individual author conducts data extraction for a given category of studies, we have developed a process for identifying studies that should be categorised under multiple outcomes and a team approach to communication to reduce bias in data extraction. 
Author affiliations

${ }^{1}$ The Schroeder Institute for Tobacco Research and Policy Studies, Legacy, Washington, DC, USA

${ }^{2}$ Department of Psychology, Virginia Commonwealth University, Richmond, Virginia, USA

${ }^{3}$ Evaluation Science and Research, Legacy, Washington, DC, USA

${ }^{4}$ Department of Health, Behavior and Society, Johns Hopkins Bloomberg School of Public Health, Baltimore, Maryland, USA

Contributors ACV conceived of the study and assumes overall responsibility for the scientific integrity of the work as a whole. ACV, AMG, COC, OG and LT developed the search strategy, and the inclusion and exclusion criteria. AMG drafted the protocol. ACV, AMG and LK will perform the title and abstract review. All authors will perform data extraction.

Funding This work was supported by the Schroeder Institute for Tobacco Research and Policy Studies at Legacy and the Robert Wood Johnson Foundation (Grant ID: 72208). Study authors are or were previously employed by Legacy.

Competing interests None declared.

Provenance and peer review Not commissioned; externally peer reviewed.

Open Access This is an Open Access article distributed in accordance with the Creative Commons Attribution Non Commercial (CC BY-NC 4.0) license, which permits others to distribute, remix, adapt, build upon this work noncommercially, and license their derivative works on different terms, provided the original work is properly cited and the use is non-commercial. See: http:// creativecommons.org/licenses/by-nc/4.0/

\section{REFERENCES}

1. Adkison SE, O'Connor RJ, Bansal-Travers M, et al. Electronic nicotine delivery systems: international tobacco control four-country survey. Am J Prev Med 2013;44:207-15.

2. Etter JF. Electronic cigarettes: a survey of users. BMC Public Health 2010;10:231.

3. Etter JF, Bullen C. Electronic cigarette: users profile, utilization, satisfaction and perceived efficacy. Addiction 2011;106: 2017-28.

4. Foulds J, Veldheer S, Berg A. Electronic cigarettes (e-cigs): views of aficionados and clinical/public health perspectives. Int $\mathrm{J}$ Clin Pract 2011;65:1037-42.

5. Gallus S, Lugo A, Pacifici R, et al. E-cigarette awareness, use, and harm perception in Italy: a national representative survey. Nicotine Tob Res 2014;16:1541-8.

6. Goniewicz ML, Lingas EO, Hajek P. Patterns of electronic cigarette use and user beliefs about their safety and benefits: an internet survey. Drug Alcohol Rev 2013;32:133-40.

7. Li J, Bullen C, Newcombe R, et al. The use and acceptability of electronic cigarettes among New Zealand smokers. $N Z$ Med $J$ 2013;126:48-57.

8. Zhu SH, Gamst A, Lee M, et al. The use and perception of electronic cigarettes and snus among the U.S. population. PLOS ONE 2013;8: e79332.

9. Bullen $\mathrm{C}$, McRobbie $\mathrm{H}$, Thornley $\mathrm{S}$, et al. Effect of an electronic nicotine delivery device (e cigarette) on desire to smoke and withdrawal, user preferences and nicotine delivery: randomised cross-over trial. Tob Control 2010;19:98-103.

10. Dawkins L, Turner J, Crowe E. Nicotine derived from the electronic cigarette improves time-based prospective memory in abstinent smokers. Psychopharmacology (Berl) 2013;227:377-84.

11. Dawkins L, Turner J, Hasna S, et al. The electronic-cigarette: effects on desire to smoke, withdrawal symptoms and cognition. Addict Behav 2012;37:970-3.

12. Etter JF, Bullen C. Saliva cotinine levels in users of electronic cigarettes. Eur Respir J 2011;38:1219-20.

13. Vansickel AR, Cobb CO, Weaver MF, et al. A clinical laboratory model for evaluating the acute effects of electronic "cigarettes": nicotine delivery profile and cardiovascular and subjective effects. Cancer Epidemiol Biomarkers Prev 2010;19:1945-53.

14. McQueen A, Tower S, Sumner W. Interviews with "vapers": implications for future research with electronic cigarettes. Nicotine Tob Res 2011;13:860-7.

15. Richardson A, Pearson $\mathrm{J}$, Xiao $\mathrm{H}$, et al. Prevalence, harm perceptions, and reasons for using noncombustible tobacco products among current and former smokers. Am J Public Health 2014;104:1437-44.

16. Dawkins L, Turner J, Roberts A, et al. 'Vaping' profiles and preferences: an online survey of electronic cigarette users. Addiction 2013;108:1115-25.

17. Dockrell M, Morrison R, Bauld L, et al. E-cigarettes: prevalence and attitudes in Great Britain. Nicotine Tob Res 2013;15:1737-44.

18. Farsalinos KE, Romagna G, Tsiapras D, et al. Characteristics, perceived side effects and benefits of electronic cigarette use: a worldwide survey of more than 19,000 consumers. Int J Environ Res Public Health 2014;11:4356-73.

19. Harrington KF, Hull NC, Akindoju O, et al. Electronic cigarette awareness, use history, and expected future use among hospitalized cigarette smokers. Nicotine Tob Res 2014;16:1512-17.

20. Kralikova E, Novak J, West O, et al. Do e-cigarettes have the potential to compete with conventional cigarettes? A survey of conventional cigarette smokers' experiences with e-cigarettes. Chest 2013:144:1609-14.

21. Vickerman KA, Carpenter KM, Altman T, et al. Use of electronic cigarettes among state tobacco cessation quitline callers. Nicotine Tob Res 2013;15:1787-91.

22. Trtchounian A, Williams M, Talbot P. Conventional and electronic cigarettes (e-cigarettes) have different smoking characteristics. Nicotine Tob Res 2010;12:905-12.

23. Williams M, Talbot $P$. Variability among electronic cigarettes in the pressure drop, airflow rate, and aerosol production. Nicotine Tob Res 2011;13:1276-83.

24. Lee YO, Kim AE. 'Vape shops' and 'E-Cigarette lounges' open across the USA to promote ENDS. Tob Control 2014. Published Online First 11 Apr 2014.

25. Abrams DB. Promise and peril of e-cigarettes: can disruptive technology make cigarettes obsolete? JAMA 2014;311: 135-6

26. Maziak W. Harm reduction at the crossroads: the case of e-cigarettes. Am J Prev Med 2014;47:505-7.

27. Benowitz NL, Goniewicz ML. The regulatory challenge of electronic cigarettes. JAMA 2013;310:685-6.

28. Food and Drug Administration. Deeming tobacco products to be subject to the Federal Food, Drug, and Cosmetic Act, as amended by the Family Smoking Prevention and Tobacco Control Act; regulations on the sale and distribution of tobacco products and required warning statements for tobacco products, 2014.

29. Burstyn I. Peering through the mist: systematic review of what the chemistry of contaminants in electronic cigarettes tells us about health risks. BMC Public Health 2014;14:18.

30. Cahn Z, Siegel M. Electronic cigarettes as a harm reduction strategy for tobacco control: a step forward or a repeat of past mistakes? $J$ Public Health Policy 2011;32:16-31.

31. Callahan-Lyon P. Electronic cigarettes: human health effects. Tob Control 2014;23(Suppl 2):ii36-40.

32. Caponnetto P, Campagna D, Papale G, et al. The emerging phenomenon of electronic cigarettes. Expert Rev Respir Med 2012;6:63-74.

33. Chang $\mathrm{H}$. Research gaps related to the environmental impacts of electronic cigarettes. Tob Control 2014;23(Suppl 2):ii54-8.

34. Durmowicz EL. The impact of electronic cigarettes on the paediatric population. Tob Control 2014;23(Suppl 2):ii41-6.

35. Evans SE, Hoffman AC. Electronic cigarettes: abuse liability, topography and subjective effects. Tob Control 2014;23(Suppl 2): ii23-9.

36. Farsalinos KE, Polosa R. Safety evaluation and risk assessment of electronic cigarettes as tobacco cigarette substitutes: a systematic review. Ther Adv Drug Saf 2014;5:67-86.

37. Gualano MR, Passi S, Bert F, et al. Electronic cigarettes: assessing the efficacy and the adverse effects through a systematic review of published studies. J Public Health (Oxf) 2014. Published Online First 9 Aug 2014. doi:10.1093/pubmed/fdu055

38. Knorst MM, Benedetto IG, Hoffmeister MC, et al. The electronic cigarette: the new cigarette of the 21st century? J Bras Pneumol 2014;40:564-72.

39. Lippi G, Favaloro EJ, Meschi T, et al. E-cigarettes and cardiovascular risk: beyond science and mysticism. Semin Thromb Hemost 2014;40:60-5.

40. Middlekauff HR, Park J, Moheimani RS. Adverse effects of cigarette and noncigarette smoke exposure on the autonomic nervous system: mechanisms and implications for cardiovascular risk. J Am Coll Cardiol 2014:64:1740-50.

41. Oh AY, Kacker A. Do electronic cigarettes impart a lower potential disease burden than conventional tobacco cigarettes? Review on e-cigarette vapor versus tobacco smoke. Laryngoscope 2014;124:2702-6. 
42. Orr MS. Electronic cigarettes in the USA: a summary of available toxicology data and suggestions for the future. Tob Control 2014;23 (Suppl 2):ii18-22.

43. Pisinger C, Dossing M. A systematic review of health effects of electronic cigarettes. Prev Med 2014;69c:248-60.

44. Schivo M, Avdalovic MV, Murin S. Non-cigarette tobacco and the lung. Clin Rev Allergy Immunol 2014:46:34-53.

45. Schroeder MJ, Hoffman AC. Electronic cigarettes and nicotine clinical pharmacology. Tob Control 2014;23(Suppl 2):ii30-5.

46. Smith JE. Electronic cigarettes: a safer alternative or potential poison? Home Healthc Nurse 2014;32:532-5.

47. Suter MA, Mastrobattista J, Sachs M, et al. Is there evidence for potential harm of electronic cigarette use in pregnancy? Birth Defects Res A Clin Mol Teratol 2015;103:186-95

48. Yang L, Rudy SF, Cheng JM, et al. Electronic cigarettes: incorporating human factors engineering into risk assessments. Tob Control 2014;23(Suppl 2):ii47-53.

49. [No authors listed]. Do electronic cigarettes help with smoking cessation? Drug Ther Bull 2014;52:126-9.

50. Franck C, Budlovsky $\mathrm{T}$, Windle $\mathrm{SB}$, et al. Electronic cigarettes in North America: history, use, and implications for smoking cessation. Circulation 2014;129:1945-52.

51. Harrell PT, Simmons VN, Correa JB, et al. Electronic nicotine delivery systems ("e-cigarettes"): review of safety and smoking cessation efficacy. Otolaryngol Head Neck Surg 2014;151:381-93.

52. Meier E, Tackett AP, Wagener TL. Effectiveness of electronic aids for smoking cessation. Curr Cardiovasc Risk Rep 2013;7:1-13.

53. Orr KK, Asal NJ. Efficacy of electronic cigarettes for smoking cessation. Ann Pharmacother 2014;48:1502-6.
54. Brown CJ, Cheng JM. Electronic cigarettes: product characterisation and design considerations. Tob Control 2014;23(Suppl 2):ii4-10.

55. Cheng T. Chemical evaluation of electronic cigarettes. Tob Control 2014;23(Suppl 2):ii11-17.

56. Pepper JK, Brewer NT. Electronic nicotine delivery system (electronic cigarette) awareness, use, reactions and beliefs: a systematic review. Tob Control 2014;23:375-84.

57. Carroll Chapman SL, Wu LT. E-cigarette prevalence and correlates of use among adolescents versus adults: a review and comparison. $J$ Psychiatr Res 2014;54:43-54.

58. Kadowaki J, Vuolo M, Kelly BC. A review of the current geographic distribution of and debate surrounding electronic cigarette clean air regulations in the United States. Health Place 2014;31c:75-82.

59. Breland AB, Spindle T, Weaver M, et al. Science and electronic cigarettes: current data, future needs. J Addict Med 2014;8: 223-33.

60. Grana RA, Ling PM, Benowitz N, et al. Electronic cigarettes. Circulation 2014;129:e490-2.

61. Hajek P, Etter JF, Benowitz N, et al. Electronic cigarettes: review of use, content, safety, effects on smokers and potential for harm and benefit. Addiction 2014;109:1801-10.

62. Palazzolo DL. Electronic cigarettes and vaping: a new challenge in clinical medicine and public health. a literature review. Front Public Health 2013;1:56.

63. Riker CA, Lee K, Darville A, et al. E-cigarettes: promise or peril? Nurs Clin North Am 2012;47:159-71.

64. Green S, Higgins JP. The Cochrane Handbook for Systematic Reviews of Interventions. West Sussex, England: John Wiley \& Sons Ltd, 2008. 